\title{
Production of zinc oxide thin films and crystals in different deposition times and investigation of their structural, optical and electronic properties
}

\author{
HALEh KANGARLOU ${ }^{1, *}$, PARISA ESMAILI ${ }^{2}$ \\ ${ }^{1}$ Department of Physics, Urmia Branch, Islamic Azad University, Urmia, Iran \\ ${ }^{2}$ Young Researchers and Elite Club, Urmia Branch, Islamic Azad University, Urmia, Iran
}

\begin{abstract}
An aqueous colloidal solution was prepared at $80{ }^{\circ} \mathrm{C}$ and $\mathrm{pH}=9$ from suitable chemical compounds to produce zinc oxide $(\mathrm{ZnO})$ crystals and thin films. The $\mathrm{ZnO}$ crystals were grown in the colloidal solution under special conditions. Their micrographs showed $\mathrm{ZnO}$ rods with hexagonal structure. The number of the rods, increased over time. The $\mathrm{ZnO}$ thin films were produced on glass substrates in the same colloidal solution using the chemical bath deposition (CBD) method in different deposition times. The produced films were post-annealed for about one hour at $400{ }^{\circ} \mathrm{C}$. Crystalline structure, phase transitions and nanostructure of the films were investigated by X-ray diffraction (XRD), scanning electron microscopy (SEM) and atomic force microscopy (AFM). $\mathrm{ZnO}$ wurtzite structure was dominant, and by increasing the deposition time, the films became more crystalline. Nanostructure of the films changed from rod to wire and transformed into pyramid-like structures. Also, morphology of the films changed and re-nucleation ocurred. Optical reflectance was measured in the wavelength of $300 \mathrm{~nm}$ to $800 \mathrm{~nm}$ with a spectrophotometer. Other optical properties and optical band gaps were calculated using Kramers-Kronig relation on reflectivity curves. Second harmonic generation was calculated by Z-scan technique. Nonlinear refraction and real part of susceptibilities were obtained. Both positive and negative nonlinear refractions appeared in the $\mathrm{ZnO}$ films. It is important for the use in optoelectronic devices. Electronic properties were assessed by the full potential linearized augmented plane wave (FP-LAPW) method, within density functional theory (DFT). In this approach, the generalized gradient approximation (GGA) was used for the exchange-correlation potential calculation. The band gap structure and density of states were calculated.
\end{abstract}

Keywords: zinc oxide; phase transitions; spectroscopy; colloidal solution; Kramers-Kronig relation

\section{Introduction}

Zinc oxide $(\mathrm{ZnO})$ is a wide-band gap II-VI semiconductor with a hexagonal wurtzite structure [1]. Among various semiconductors, $\mathrm{ZnO}$ has gained considerable attention due to its unique properties and applications. $\mathrm{ZnO}$ nanostructures (NSs) are of intense interest since they can be grown with different morphologies by a variety of methods. ZnO naturally exhibits n-type semiconductor polarity due to native defects such as oxygen vacancies and zinc interstitials. P-type doping of $\mathrm{ZnO}$ is still a challenging problem, hindering the possibility of manufacturing $\mathrm{ZnO}$ p-n homojunction devices. $\mathrm{ZnO}$ is an important wide-band gap semiconductor with many useful

*E-mail: h.kangarlou@iaurmia.ac.ir properties [2], such as piezoelectricity [3], optical absorption [4], photoluminescence [5], and sensitivity to gases [6] and chemical agents. Also, its nanostructures are desirable for the use in microelectronic devices, as well as in many applications, including, chemical sensing [7], biological diagnosis, energy conversion [8], energy storage, light emitting, and optical storages. These are factors which further contribute to the resurgent attention in $\mathrm{ZnO}$. From a technological point of view, $\mathrm{ZnO}$ may be prepared in a form of films by different deposition techniques such as sol-gel [9], chemical vapor deposition (CVD) [10], physical vapor deposition (PVD) [11], sputtering [12], electrodeposition [13] and ink-jet printing [14]. Optical (both linear and nonlinear) properties are generally influenced by a specific growth technique and by deposition parameters. The second order optical 
response expected in bulk $\mathrm{ZnO}$ noncentrosymmetric crystals is not worth being shown in $\mathrm{ZnO}$ films grown by laser deposition, reactive sputtering and spray pyrolysis. The hydrothermal growth technique is promising due to its low cost and for scaling up the synthesis of nanostructures. The chemical bath deposition (CBD) method is an example of the hydrothermal methods. By studying the reflectance spectra of films deposited on solid surfaces, optical constants for the films (real and imaginary part of refractive index $\mathrm{n}$ and $\mathrm{k}$ ) can be determined [15]. There are many different methods for determining the optical constants of a material. One of the most common techniques is Kramers-Kronig analysis which has been used to determine the optical constants over the whole measurement range [16]. Development in linear methods for solving the band structure problem during the last two decades has totally resolved the limitations that were present in other contemporary band structure techniques. Linear methods are used to calculate a wide range of electronic properties. Recent studies have revealed that $\mathrm{ZnO}$ thin films have a strong nonlinear secondorder susceptibility $\chi^{(3)}$ and hence, can be used for efficient second harmonic generation [18, 19]. The full potential linearized augmented plane wave (FP-LAPW) [17] is a powerful theoretical method to determine the electronic properties of investigated compounds.

In this study, we have used a colloidal aqueous solution for development of $\mathrm{ZnO}$ crystals. The CBD method was also used for synthesis of $\mathrm{ZnO}$ thin films in the same colloidal solution, with similar deposition parameters such as growth temperature, $\mathrm{pH}$ value and material concentration, but in different chemical deposition times. According to the author's knowledge, there is no report about simultaneous comparison of structural, optical and electronic properties of $\mathrm{ZnO}$ thin films prepared by $\mathrm{CBD}$ method. The properties of the $\mathrm{ZnO}$ thin films were systematically investigated as a function of deposition time. The objective of this research includes detailed nanostructural characterization of the coated films. The films have been characterized by different techniques such as X-ray diffraction (XRD), scanning electron microscopy (SEM), atomic force microscopy (AFM), spectrophotometry, Kramers-Kronig relation and Z-scan technique. Also, the FP-LAPW method was used to calculate band structure and density of states of the $\mathrm{ZnO}$ films.

\section{Experimental}

Prior to chemical deposition, substrate cleaning is a necessary step. Standard $1 \mathrm{~mm}$ thick glass slides were used as substrates. Acetone, isopropanol and deionized (DI) water were separately used in ultrasonic bath to clean the substrates. $0.5 \mathrm{mM}$ of zinc acetate $\left(\mathrm{Zn}\left(\mathrm{CH}_{3} \mathrm{COO}\right)_{2}\right)$ solution, ammonia solution $\left(\mathrm{NH}_{4} \mathrm{OH}\right)$ and thiourea $\left(\mathrm{CS}\left(\mathrm{NH}_{2}\right)_{2}\right)$ were separately prepared as aqueous solution in several flasks. The formed mixtures were thoroughly stirred for one minute in order to dissolve all ingredients and get them homogeneous. Immediately, colloidal aqueous solutions appeared. The chemical formula to produce the $\mathrm{ZnO}$ thin films and nanostructures is as follows:

$$
\begin{aligned}
& 2 \mathrm{NH}_{3}+\mathrm{H}_{2} \mathrm{O} \leftrightarrow 2 \mathrm{NH}_{4}^{+}+2 \mathrm{OH}^{-} \\
& \mathrm{Zn}\left(\mathrm{CH}_{3} \mathrm{COO}\right)_{2}+4 \mathrm{NH}_{4}^{+} \leftrightarrow \mathrm{Zn}\left(\mathrm{NH}_{3}\right)_{4}^{2+} \\
& +2 \mathrm{CH}_{3} \mathrm{COOH}+2 \mathrm{H}^{+} \\
& \mathrm{H}_{2} \mathrm{O} \leftrightarrow \mathrm{OH}^{-}+\mathrm{H}^{+} \mathrm{Zn}\left(\mathrm{NH}_{3}\right)_{4}^{2+}+2 \mathrm{OH}^{-} \\
& \rightarrow \mathrm{ZnO}+\mathrm{H}_{2} \mathrm{O}+4 \mathrm{NH}_{3}
\end{aligned}
$$

All the flasks were heated at $80{ }^{\circ} \mathrm{C}$. For synthesis of the $\mathrm{ZnO}$ crystals, the reaction flasks were kept at $80{ }^{\circ} \mathrm{C}$ without stirring for about one hour. Immediately, the reaction flasks were fixed under special conditions (atmospheric pressure and near $0{ }^{\circ} \mathrm{C}$ temperature) in a stable position. The $\mathrm{ZnO}$ crystals were also grown in these conditions. To produce the $\mathrm{ZnO}$ thin films, the flasks were continuously stirred. The cleaned substrates were maintained vertically in the reaction flasks for one, two and three-hour deposition times. The produced $\mathrm{ZnO}$ thin films were post-annealed at $400{ }^{\circ} \mathrm{C}$ for about one hour. Micrograph pictures of the $\mathrm{ZnO}$ crystals were obtained by using BX43-OLYMPUS optical microscope. Crystal and phase structure of the deposited $\mathrm{ZnO}$ films were identified using an $\mathrm{X}$-ray X'Pert MPD diffractometer $(\mathrm{CuK} \alpha$ radiation, $\lambda=0.15406 \mathrm{~nm}$ ) with a step size of 0.03 and 
count time of $1 \mathrm{~s}$ per step. Nanostructures were investigated by SEM (S-3400, Hitachi, Japan). Surface physical morphology was obtained by means of AFM (Dual Scope ${ }^{\mathrm{TM}}$ DS, 95- $\frac{200}{50}$ ). Reflectance of the films was determined with UV-Vis spectrophotometer (Hitachi, U-3310). Kramers-Kronig relations were derived to calculate optical properties such as $\mathrm{n}, \mathrm{k}, \sigma_{1},-\sigma_{2}$ and optical band gap energy. $\mathrm{Z}$-scan technique developed by Bahae et al. is a single beam method for measuring the sign and magnitude of a nonlinear refractive index $n_{2}[20,21]$. A Q-switched Nd:YAG laser (Spectra Physics LAB$1760.532 \mathrm{~nm}, 7 \mathrm{~ns}, 10 \mathrm{~Hz}$ ) was used as the light source. The FP-LAPW method from Wien2k package was used to calculate the band structure and density of states.

\section{Result and discussion}

\subsection{Crystal growth in colloidal aqueous solution}

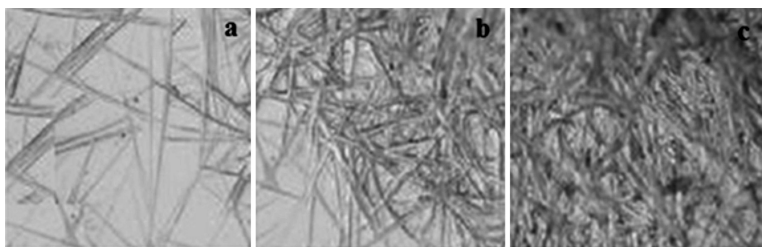

Fig. 1. The micrograph pictures of $\mathrm{ZnO}$ crystals obtained in colloidal aqueous solution (a) 2 days, (b) 4 days and (c) 7 days after experiment.

Fig. 1 depicts the $\mathrm{ZnO}$ crystals after two, four and seven days of growth, respectively. In all the micrograph photos, the $\mathrm{ZnO}$ rod structures are visible, and by increasing the time of growth, number of rods increases and becomes denser. The results are in agreement with structural analysis that will be presented.

\subsection{Structural properties of $\mathrm{ZnO}$ thin films}

\subsubsection{X-ray diffraction analysis}

Fig. 2 shows the XRD patterns of $\mathrm{ZnO}$ thin films produced in this work. $\mathrm{ZnO}$ has two different crystal structures: cubic and wurtzite (hexagonal) lattices. In this study, the wurtzite (hexagonal)

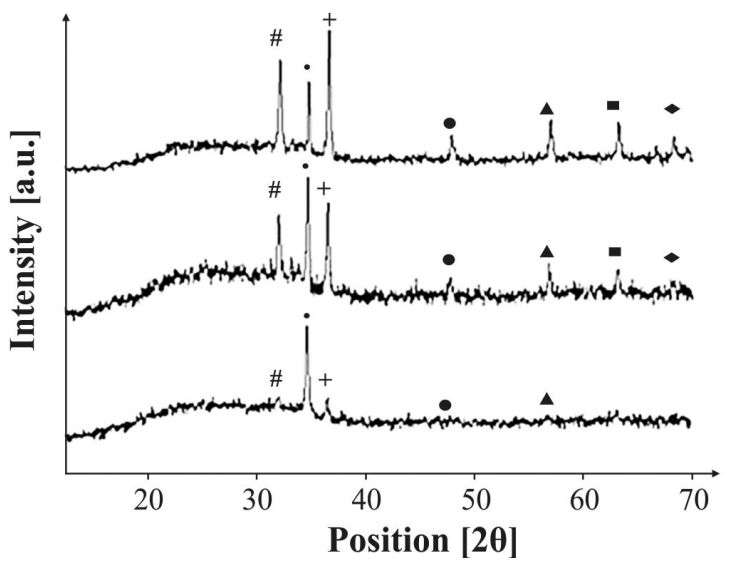

Fig. 2. XRD patterns of $\mathrm{ZnO}$ thin films produced by CBD method: (a) 1 hour, (b) 2 hours and (c) 3 hours.

structure was the prominent structure, although for the one-hour-deposited film, small peaks related to the cubic structure appeared. As we know, deposition methods and annealing temperatures highly affect crystalline orientations. By increasing the time of deposition, phase transition takes place and films become more crystalline.

Table 1 shows XRD diffraction peaks according to JCPDS Card No. 36.1451, corresponding to (4 $\left.\begin{array}{lll}4 & 0\end{array}\right)$ and (4 40 ) reticular planes which are similar to the ones reported by Goncalves et al. [22]. According to the Scherrer formula, the increase in grain size in a film leads to decrease in FWHM of XRD spectra [6]. Similarly, for the film produced in this work, by increasing the chemical deposition time, hence the size of grains, XRD peaks became narrower (FWHM decrease). The noisy background and a wide peak at $20^{\circ}$ to $30^{\circ}$ come from the amorphous $\mathrm{SiO}_{2}$ substrate. The interplanar distances for wurtzite phases of $\mathrm{ZnO}$ thin films were assessed by the position of $\mathrm{K} \alpha$ component of all the most intensive lines registered in the XRD patterns. The crystallite size was estimated from the FWHM of these peaks using the Scherrer formula [23]:

$$
D=\frac{k \lambda}{\beta \cos \theta}
$$

where $\mathrm{D}$ is the crystallite size, $\mathrm{k}$ is a constant taken to be $0.94, \beta$ is the full width at half maximum (FWHM) and $\lambda$ is the wave length of the X-ray. 
Table 1. XRD diffraction peaks of $\mathrm{ZnO}$ films.

\begin{tabular}{|c|c|c|c|c|}
\hline 2 & $(\mathrm{~h} \mathrm{k} \mathrm{l})$ & Sign & Sample & Crystal structure \\
\hline 32 & $\left(\begin{array}{lll}1 & 0 & 0\end{array}\right)$ & \# & I, II, III & wurtzite \\
\hline 34.5 & $\left(\begin{array}{lll}0 & 0 & 2\end{array}\right)$ & $*$ & I, II, III & wurtzite \\
\hline 36.4 & $\left(\begin{array}{lll}1 & 0 & 1\end{array}\right)$ & + & I, II, III & wurtzite \\
\hline 47.84 & $\left(\begin{array}{lll}1 & 0 & 2\end{array}\right)$ & $\bullet$ & I, II, III & $\begin{array}{l}\text { cubic } \\
\text { wurtzite }\end{array}$ \\
\hline 56.72 & $\left(\begin{array}{lll}1 & 1 & 0\end{array}\right)$ & $\boldsymbol{\Delta}$ & I, II, III & $\begin{array}{c}\text { cubic } \\
\text { wurtzite }\end{array}$ \\
\hline 62.8 & $\left(\begin{array}{lll}1 & 0 & 3\end{array}\right)$ & $\mathbf{\square}$ & II, III & wurtzite \\
\hline 68.33 & $\left(\begin{array}{lll}1 & 1 & 2\end{array}\right)$ & $\diamond$ & II, III & wurtzite \\
\hline
\end{tabular}

Strain in the films was calculated from FWHM of the prominent peaks using the relation:

$$
\varepsilon=\frac{\beta \cos \theta}{4}
$$

The values of strain and grain sizes are shown in Table 2.

\subsubsection{Scanning electron microscopy analysis}

The nanostructures of the $\mathrm{ZnO}$ films were investigated by using SEM which is an important technique to study structures at nanoscale. The SEM images of the $\mathrm{ZnO}$ thin films grown at different chemical deposition times are demonstrated in Fig. 3.

It is seen that, the $\mathrm{ZnO}$ grains covering the substrate grew perpendicular, parallel and oblique to the substrate. After one hour deposition, the $\mathrm{ZnO}$ NRs with well identified hexagonal facets were obtained and shown in Fig. 3a. The $\mathrm{ZnO}$ grains with $37 \mathrm{~nm}$ size are hexagonal in cross-section, densely packed, and most vertically-aligned. This growth habit is commonly observed for $\mathrm{ZnO}$ nanorods grown via CBD method. Fig. $3 b$ shows the SEM image of the $\mathrm{ZnO}$ nanostructures produced in twohour chemical deposition time. The $\mathrm{ZnO}$ nanostructures are composed of nanowires with a grain size of $68 \mathrm{~nm}$. The nanorods grown in the deposition time of one hour (Fig. 3(a)) are shorter in length and wider than those grown in two hours (Fig. 3b). Fig. 3c displays the $\mathrm{ZnO}$ thin film obtained after three hours of drposition. The tips of the produced nanostructures at the inlet are highly tapered and form pyramid-like structures with $75 \mathrm{~nm}$ grain sizes. The changes in growth

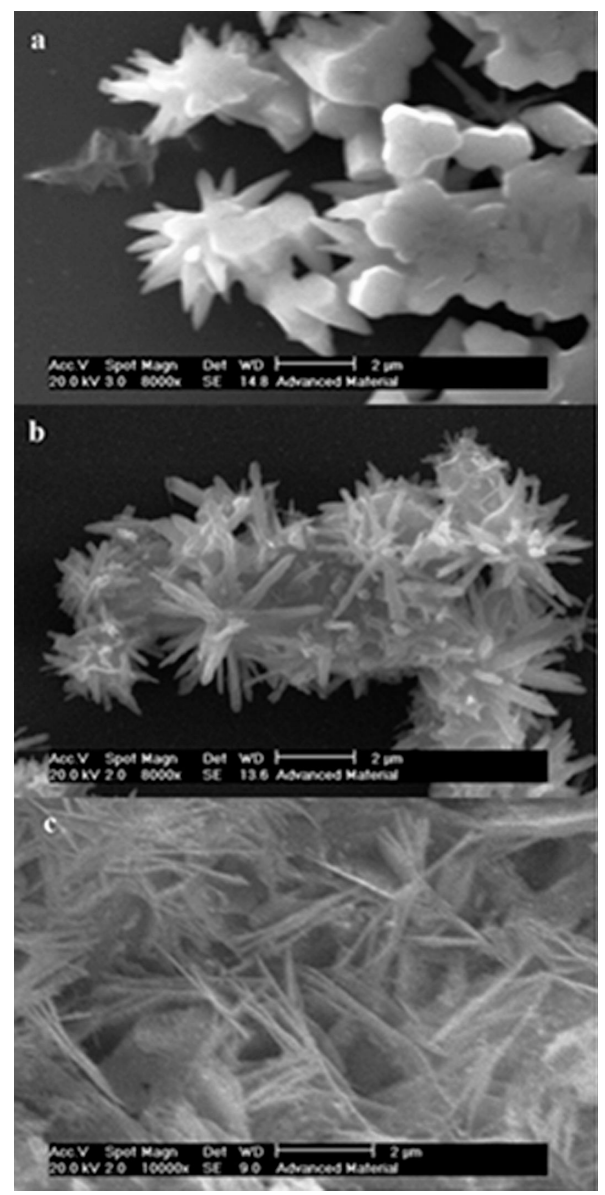

Fig. 3. Scanning electron microscopy images of $\mathrm{ZnO}$ thin films produced by CBD method for: (a) 1 hour, (b) 2 hours and (c) 3 hours.

habit from a rod to a wire and to pyramid-like structures are caused by changing the growth time and growth velocities of the $\mathrm{ZnO}$ crystal faces. The SEM images are completely in agreement with 
Table 2. General characteristics of $\mathrm{ZnO}$ films.

\begin{tabular}{ccccc}
\hline Sample & Deposition time & Cluster size $[\mu \mathrm{m}]$ & $\begin{array}{c}\text { Strain } \\
{[\%]}\end{array}$ & Grain size $[\mathrm{nm}]$ \\
\hline \hline I & $1 \mathrm{~h}$ & 0.5 & 1.01 & 37 \\
II & $2 \mathrm{~h}$ & 1 & 0.43 & 68 \\
III & $3 \mathrm{~h}$ & 1.6 & 0.29 & 75 \\
\hline
\end{tabular}

the XRD diffraction patterns, and different nanostructure shapes result from different chemical deposition times.

\subsubsection{Atomic force microscopy analysis}
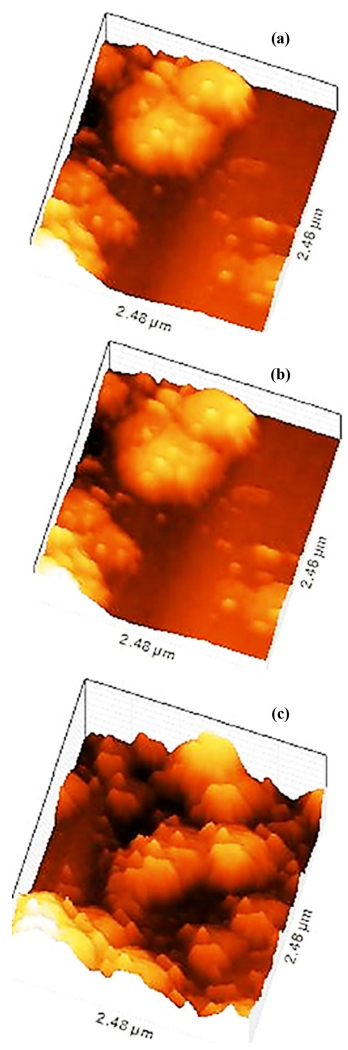

Fig. 4. AFM images of $\mathrm{ZnO}$ films produced by $\mathrm{CBD}$ method for: (a) 1 hour, (b) 2 hours and (c) 3 hours.

Fig. 4 shows atomic force microscopy images of the $\mathrm{ZnO}$ films produced by the CBD method. In Fig. 4a, conical $\mathrm{ZnO}$ grains along with voids between them cover the surface of the substrate. By increasing chemical deposition time to two hours, morphology of the film completely changed and hill-like clusters along with re-nucleation process (bright spots) appeared. Due to supersaturation process that happens most of all in CBD method, fraction of voids increased. The grains have desorbed to the colloidal aqueous solution. The time for desorption of the grains in this method depends on the kind of deposited material. Fig. 4c shows the AFM image of the $\mathrm{ZnO}$ film after three-hour chemical deposition time. As can be seen, the film became more complete and denser, re-nucleation process was more distinct and the fraction of voids decreased. The grains became bigger and cluster sizes increased with increasing chemical deposition time. The cluster sizes were measured by AFM software and are shown in Table 2.

\subsection{Optical properties}

\subsubsection{Linear optics, Kramers- Kronig rela- tions}

In this work, Kramers-Kronig relation was used to calculate the phase angle $\theta(\mathrm{E})$ as was extensively explained in our earlier works $[15,16]$ :

$$
\begin{aligned}
& \theta(E)=-\frac{E}{\pi} \int_{0}^{E_{2}} \frac{\ln R(E)-\ln R\left(E_{0}\right)}{E^{2}-E_{0}^{2}} d E \\
& +\frac{1}{2 \pi} \ln \left[\frac{R(E)}{R\left(E_{2}\right)}\right] \ln \frac{E_{2}+E}{\left|E_{2}-E\right|} \\
& +\frac{1}{\pi} \sum_{n=0}^{\infty}\left[4\left(\frac{E}{E_{2}}\right)^{2 n+1}\right](2 n+1)
\end{aligned}
$$

where $\mathrm{E}$ is the photon energy, $\mathrm{E}_{2}$ the asymptotic limitation of free-electron energy and $R(E)$ is the reflectance. Hence, the $\theta(\mathrm{E})$ function can be calculated. Then, the real and imaginary parts of the refractive index were calculated, from which other parameters were obtained. The results for optical properties are as follows:

Fig. 5 shows the reflectance curves of the $\mathrm{ZnO}$ films produced in this work. As can be seen, 


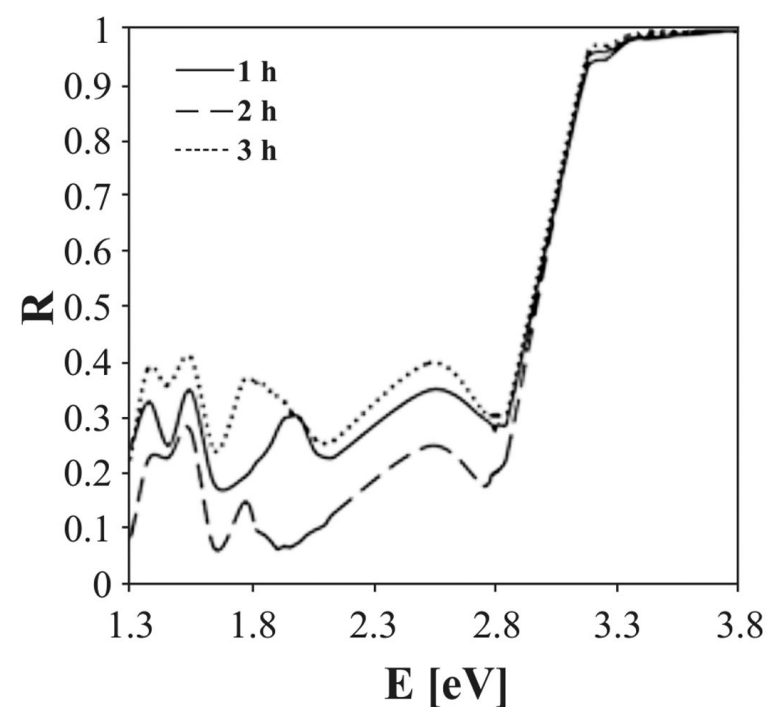

Fig. 5. Reflectance curves of $\mathrm{ZnO}$ films obtained at different chemical deposition times.

the $\mathrm{ZnO}$ film produced in three hours has the highest reflectance, whereas the one produced in two hours shows the lowest reflectance. The results are similar to those reported in the work by Wen et al. [24], and are consistent with structural analysis. We can observe a decreased fraction of voids and completely configured film for three-hour deposition time and also, supersaturation for adsorption of the grains to the colloidal aqueous solution and increased fraction of voids for two-hour deposition time. In Fig. 6a, the real part of the refractive index $n$ is depicted. All the curves have the same trend. By increasing the time of chemical deposition in the first step (Sample II), diluted film was produced, so $n$ decreased while in the second step (Sample III), dense and complete film was achieved, therefore $n$ increased. Fig. $6 \mathrm{~b}$ displays the imaginary part of the refractive index. In general, the film produced in 3 hours, and the film produced in 2 hours had the highest and the lowest, extinction efficiency. From $1.4 \mathrm{eV}$ up to $2.9 \mathrm{eV}$, peculiarities correlate with each other, due to the competition between desorption and adsorption of grains by increasing the deposition time. Fig. 7a shows the real part of conductivity $\sigma_{1}$. In general, the three-hour deposited film and two-hour deposited film show the highest and the lowest conductivity,
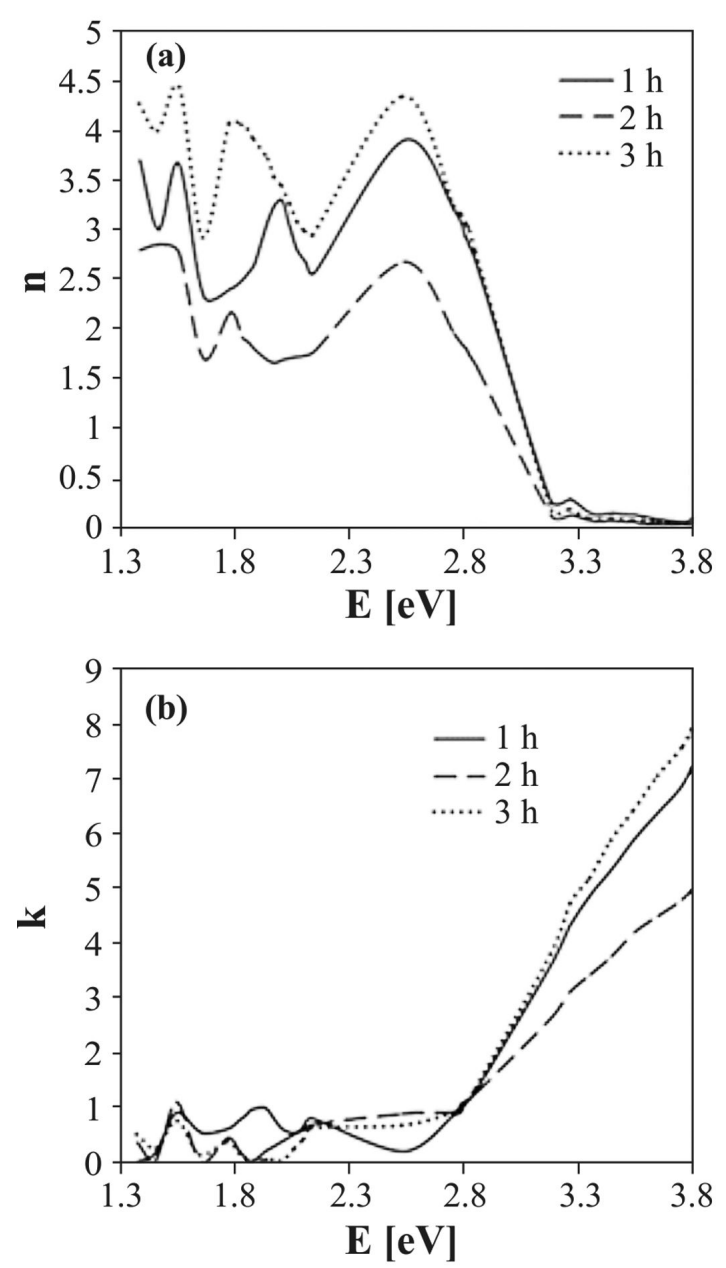

Fig. 6. The real part (a) and imaginary part (b) of refractive index of $\mathrm{ZnO}$ films obtained at different chemical deposition times.

respectively. The same competition can be observed in $\sigma_{2}$ curves. The imaginary part of conductivity $\sigma_{2}$ is shown in Fig. $7 \mathrm{~b}$. The $-\sigma_{2}$ curves show the same trend as that of the $\sigma_{1}$ curves.

Fig. 8 displays the experimental band gap energy. The wurtzite structure $\mathrm{ZnO}$ has a direct band gap, so the optical band gap Eg of the films can be calculated by following equation [25]:

$$
(\alpha h v)^{2}=(h v-E g)
$$

where $\mathrm{h} v$ is the photon energy and $\alpha$ is the experimental absorption coefficient given as:

$$
\alpha=\frac{2 \mathrm{E}}{\hbar \mathrm{c}} \mathrm{k}(\mathrm{E})
$$



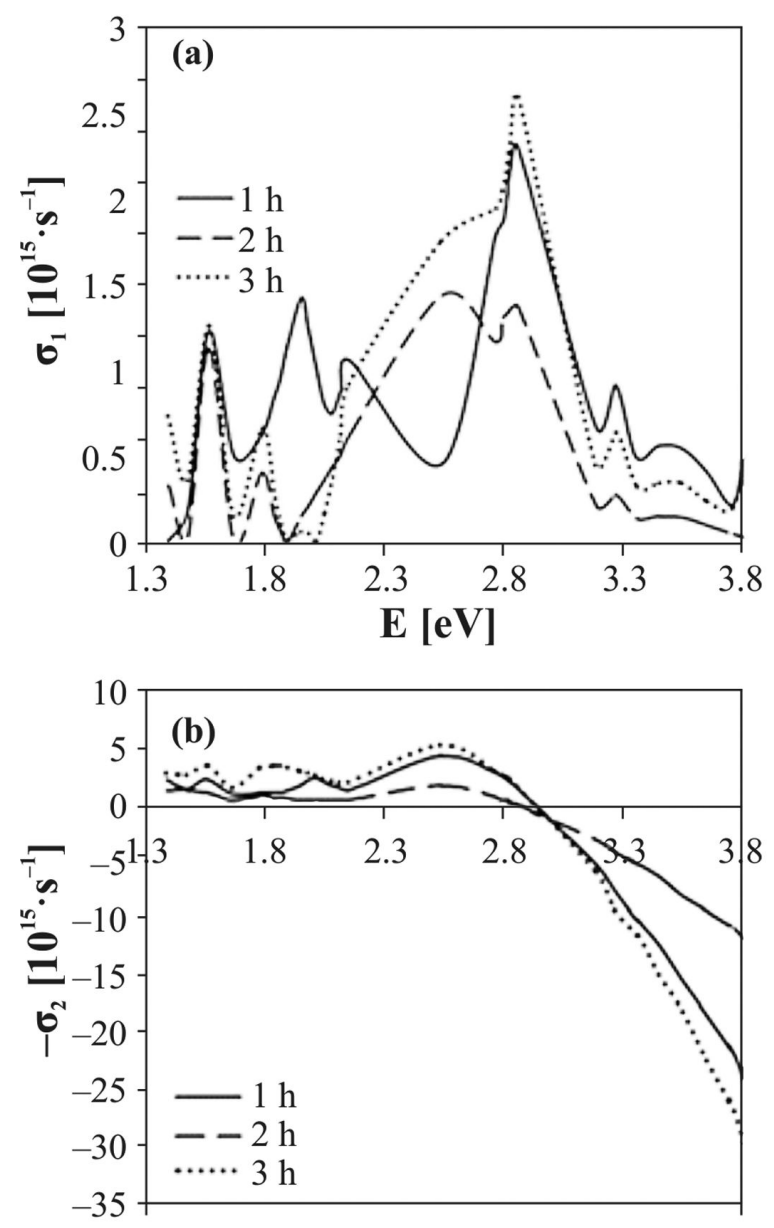

\section{$\mathbf{E}[\mathrm{eV}]$}

Fig. 7. Real part (a) and imaginary part (b) of conductivity of $\mathrm{ZnO}$ films obtained at different chemical deposition times.

Table 3. Band gap energy values of $\mathrm{ZnO}$ films.

\begin{tabular}{cc}
\hline Sample & Band gap energy [eV] \\
\hline \hline I & 3.11 \\
II & 3.21 \\
III & 3.08 \\
DFT method & 2 \\
\hline
\end{tabular}

where $\mathrm{c}$ is the velocity of light and $\mathrm{k}(\mathrm{E})$ is the imaginary part of the refractive index.

Table 3 shows the values of band energy for the films produced in this work. In agreement with conductivity, Sample III has the lowest band gap value, whereas Sample II has the highest band gap

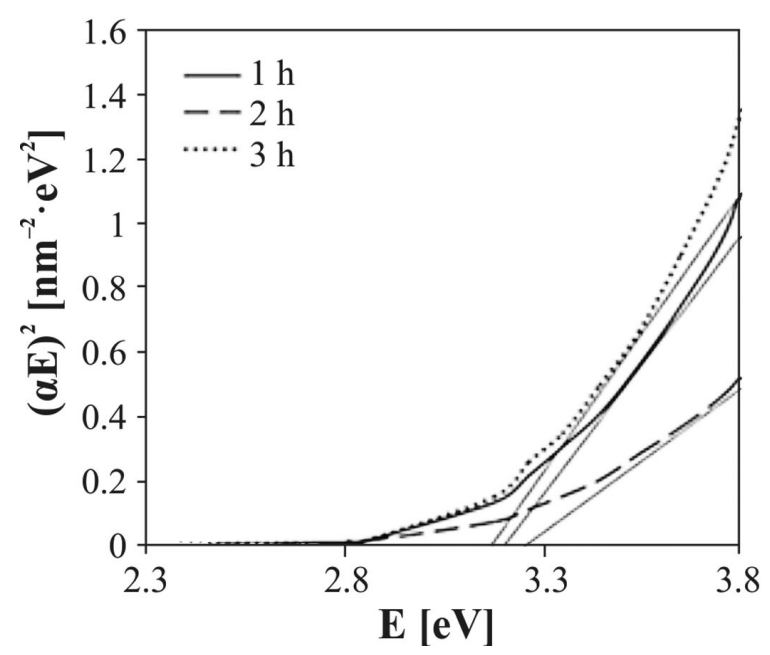

Fig. 8. The band gap curves of $\mathrm{ZnO}$ films different chemical obtained at deposition times.

value. According to chemical stochiometric formula $(\mathrm{ZnO})$ and the results of conductivity and band gap, Sample II contain the highest number of negative ions $\mathrm{O}^{-}$, while Sample III contain the highest number of positive ions $\mathrm{Zn}^{+}$.

\subsubsection{Nonlinear optics, Z-scan technique}

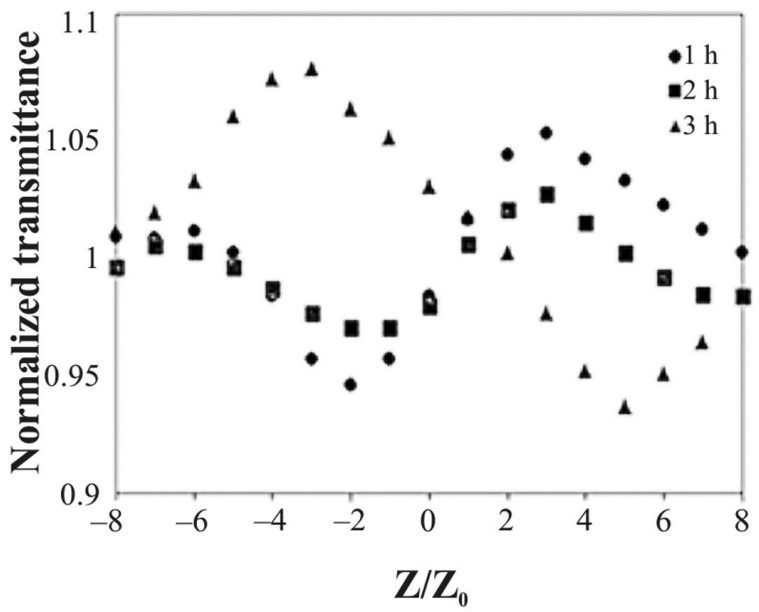

Fig. 9. Normalized transmittance curves of $\mathrm{ZnO}$ films obtained at different chemical deposition times.

Fig. 9 displays normalized transmittance obtained in this study by Z-scan $\lambda=532 \mathrm{~nm}$ analysis. As can be seen, both the positive and negative nonlinear refractions have appeared. 
For Samples I and II, nonlinear refraction is positive, which means that self-focusing occurs and the films can be used as convex lens. Sample III acts as concave lens, which is caused by the negative value of nonlinear refraction.

Difference between the normalized transmittance at the peak and valley can be calculated from equation 7 [26]:

$$
\Delta T_{p-v} \simeq 0.406(1-s)^{0.27} \Delta \varnothing_{0}
$$

where $\Delta \varnothing$ is the peak nonlinear phase change, and $s$ is the transmittance of aperture in the absence of a sample. The nonlinear refractive index is obtained from:

$$
\Delta \varnothing=\frac{2 \pi}{\lambda} n_{2} I_{0}(L) L_{e f f}
$$

where $\lambda$ is the laser wavelength, $L_{\text {eff }}$ is the effective length given by, $\mathrm{L}_{\text {eff }}=\frac{\left(1-\mathrm{e}^{-\alpha \mathrm{L}}\right)}{\alpha}, \alpha$ is the linear absorption coefficient that has been calculated in linear optics by the Kramers-Kronig method and L is the sample length.

The real part of the nonlinear susceptibility $\operatorname{Re} \chi^{(3)}$ is given by the following equation:

$$
R_{\xi}^{3}=\frac{n_{0} n_{2}}{3 \pi}
$$

where $\mathrm{n}_{0}=2.008$ is the general linear refractive index of the $\mathrm{ZnO}$ semiconductor.

Table 4 shows the value of linear and nonlinear refractive indices and nonlinear susceptibility at $\lambda=532 \mathrm{~nm}$ wavelength for the films produced in this work. Binary NLO results of this work are related to the CBD method and type of chemical bonds and energies between atoms. Therefore, we can use the produced films in optoelectronic devices.

\subsection{Electronic properties}

Density-functional theory (DFT) calculations have been performed using the FP-LAPW method. We have used generalized gradient approximation (GGA) [27] in the form of the PBEsol functional [28], implemented in the WIEN2K package [29]. The muffin tin radius for $\mathrm{Zn}$ and $\mathrm{O}$ has been set to 1.99 and 1.71 a.u., respectively. We

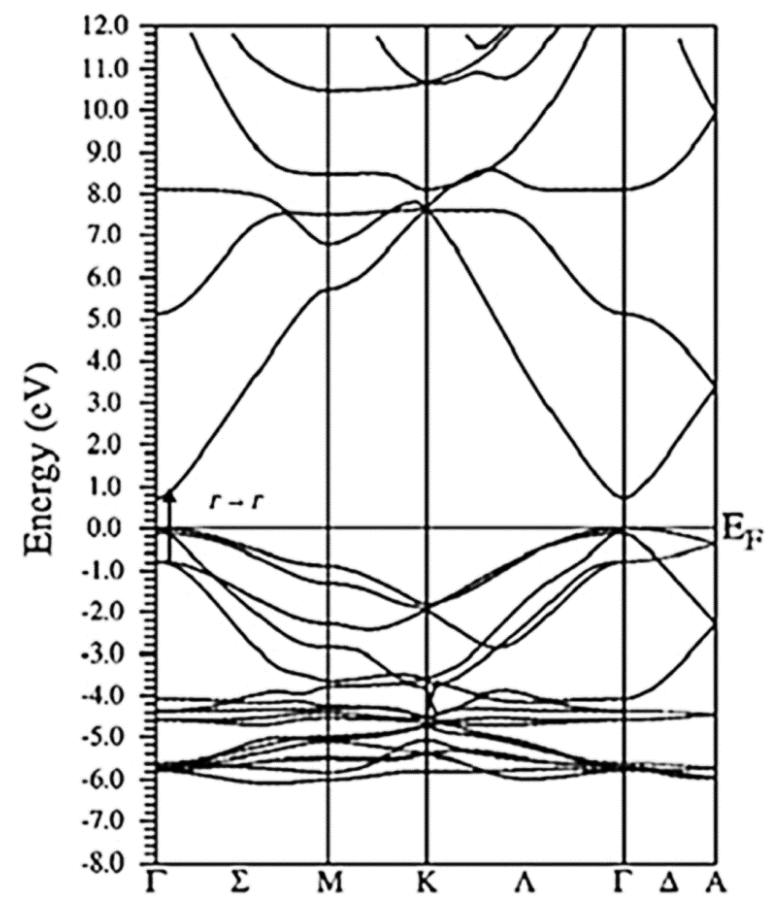

Fig. 10. Calculated electronic band structure of zinc oxide.

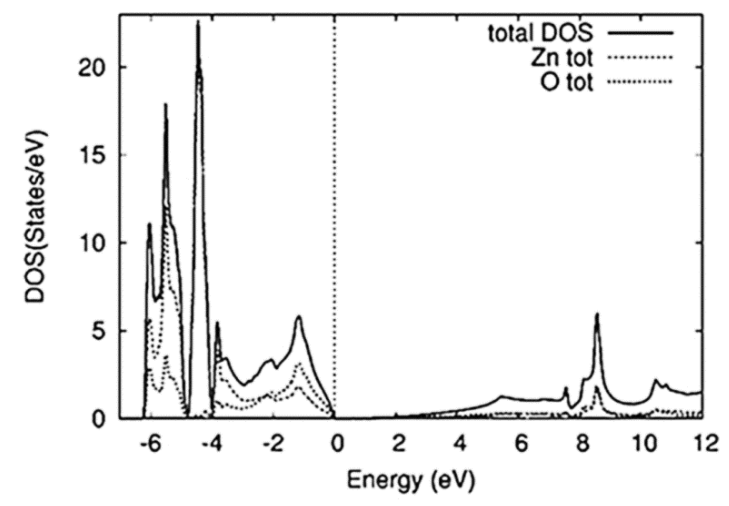

Fig. 11. Calculated DOS of zinc oxide.

have set $\mathrm{R}_{\mathrm{Kmax}}=7.5$, optimized the $\mathrm{ZnO}$ lattice parameters for a k-point grid of $(24 \times 24 \times 24)$ and obtained equilibrium values of $\mathrm{a}=2.239 \AA$ and $\mathrm{c}=5.228 \AA$, comparable with experimental values of $\mathrm{a}=3.25 \AA$ and $\mathrm{c}=5.207 \AA$ [30]. The band structures are shown in Fig. 10, and density of states calculated by GGA-PBEsol method is presented in Fig. 11. Direct transition from $\Gamma \rightarrow$ $\Gamma$ is clear. The value of the band gap has been calculated as $2 \mathrm{eV}$. 
Table 4. Linear and nonlinear refractive index and nonlinear susceptibility values.

\begin{tabular}{cccc}
\hline Sample & $\mathrm{n}_{0}$ & $\ln _{2} \mid\left(\frac{\mathrm{m}^{2}}{\mathrm{w}}\right)$ & $\mathrm{R}_{\mathrm{xi}}^{3}\left(\frac{\mathrm{m}^{2}}{\mathrm{w}}\right)$ \\
\hline \hline I & 3.4 & $2.54 \times 10^{-14}$ & $5.41 \times 10^{-5}$ \\
II & 2.4 & $2.02 \times 10^{-14}$ & $4.32 \times 10^{-5}$ \\
III & 3.9 & $2.79 \times 10^{-14}$ & $5.94 \times 10^{-5}$ \\
\hline
\end{tabular}

\section{Conclusions}

$\mathrm{ZnO}$ crystals and thin films were produced from suitable aqueous colloidal solutions. The $\mathrm{ZnO}$ crystals were grown at atmospheric pressure and near zero temperature conditions. The films were deposited from the same colloidal solution using CBD method, in different deposition times $(1 \mathrm{~h}$, $2 \mathrm{~h}$ and $3 \mathrm{~h}$ ). The produced thin films were postannealed at $400{ }^{\circ} \mathrm{C}$ for about one hour. Micrographs of the $\mathrm{ZnO}$ crystals, depict $\mathrm{ZnO}$ rods with hexagonal structure that increase in number with time. Crystallographic directions of the $\mathrm{ZnO}$ films and grain size were investigated by XRD analysis. The wurtzite structure was dominant, and with increasing the deposition time, number of wurtzite peaks increased and they became sharper. Nanostructure of the $\mathrm{ZnO}$ films was investigated by SEM analysis. The SEM images showed that the nanorods (in Sample I), nanowires (in Sample II) and pyramid-like structures (in Sample III) have grown in the films. The morphology of produced films was studied by AFM, and it was changing with the deposition time. Due to supersaturation process, the hemispherical grains (in Sample I) were converted into hill-like grains and as a result fraction of the voids increased (Sample II). Renucleation process and decreasing fraction of the voids led to more complete film for Sample III. Optical properties of the produced films were calculated by Kramers-Kronig relation on reflectivity curves in visible light wavelength range. Supersaturation process, desorption of grains and increased fraction of voids in Sample II on the one hand, and preparation of complete film, re-nucleation and decreased fraction of voids in Sample III on the other hand, resulted in increasing trend for $\mathrm{n}, \mathrm{k}, \sigma_{1}$ and $-\sigma_{2}$ in Sample III and decreasing one in Sample II. At some energies, the curves crossed each other, which resulted from the competition between the desorbing and adsorbing grains in the films. Experimental band gap decreased for sample II, meaning that the film in Sample II was more dielectric than that in Sample I and Sample III. By increasing deposition time, the ratio of positive ions $\mathrm{Zn}^{+}$was increased, but conversely, the ratio of negative ions $\mathrm{O}^{-}$was decreased which was in agreement with the conductivity curves and band gap values. The nonlinear behavior of the films was confirmed by the Z-scan analysis. A rare event occurred in the produced films. Sample I and Sample II had positive nonlinear refraction, while for Sample III, $\mathrm{n}_{2}$ was negative. It means that we can use these films in optoelectronic devices. The value of nonlinear refraction and real part of susceptibility were calculated and compared with the linear refraction index. Electronic properties were calculated by the FPLAPW method within the DFT. In this approach, the GGA was used for the exchange-correlation potential calculations. The band gap structure and density of states were plotted.

\section{References}

[1] Ryu R.Y., Lee S.T., Lubgubanetal J.A., Appl. Phys. Lett., 87 (2005), 153504.

[2] Kuo M.L., Poxson D.J., Kim Y.S., Mont F.W., KIM J.K., Schubert E F., LiN S.Y., Opt. Lett., 33 (2008), 2527.

[3] Bouhafs D., Moussi A., Chikouche A., Ruiz J.M., Sol. Energ. Mat. Sol. C., 52 (1998), 79.

[4] Kim J.K., Chhajed S., Schubert M.F., SchuBERT E.F., Fischer A.J., CRAWford M.H., ChO J., Kim H., Sone C., Adv. Mater, 20 (2008), 801.

[5] Chen L., Yang H., Tao M., Zhou W., Proc. SPIE, 7046 (2008), 704608.

[6] Lee Y.J., Ruby D.S., Peters D.W., MCKenzie B.B., HsU J.W.P., Nano Lett., 8 (2008), 1501.

[7] TANG Y.B., Chen Z.H., Song H.S., LeE C.S., Cong H.T., Cheng H.M., Zhang W.J., Bello I., LEE S.T., Nano Lett., 8 (2008), 4191.

[8] Chen J.Y., Sun K.W., Sol. Energ. Mat. Sol. C., 94 (2010), 930. 
[9] Kashef M., Usman Ali M.S., Abdulgafour M.E., Hashim H.I., Willander U., Hassan M., Phys. Status Solidi A, 209 (2012), 143.

[10] Li B.S., LiU Y.C., Shen D.Z., Zhang J.Y., LU Y.M., FAN X.W., Cryst. Growth, 249 (2003), 179.

[11] Wang L., Zhang X., Zhao S., Zhou G., Zhou Y., Qi J., Appl. Phys. Lett., 86 (2005), 024108.

[12] Deng B., Yan X., Wei Q., Gao W., Mater. Charact., 58 (2007), 854.

[13] Chen Z., Tang Y., Zhang L., Luo L., Acta, 51 (2006), 5870.

[14] Shen W., Zhao Y., Zhang C., Thin Solid Films, 483 (2005), 382.

[15] Kangarlou H., Motallebi Aghgonbad M., AbDollahi A., Mater. Sci. Semicond. Proc., 1 (2015), 1.

[16] Kangarlou H., Motallebi Aghgonbad M., $O p$ tik, 125 (2014), 5532.

[17] Singh D. J., Plane Waves, Pseudo potentials and the $L A P W$ Method, Kluwer Academic Publishers, BostonDordrecht-London, 1994.

[18] Newmann U., Grunwald R., Griedner U., Steinmeyer G., Appl. Phys. Lett., 84 (2004), 170.

[19] Wang G., Kiehne G.T., Wong G.K.L., Ketterson J.B., LiU X., Chang R.P.H., Appl. Phys. Lett., 80 (2002), 401.

[20] Bahae M S., Said A.A., Stryland van E.W., Opt. Lett., 14 (1989), 955.
[21] Bahae M.S., Said A.A., Wei T.H., Hagan D.J. STRYLAND VAN E.W., IEEE J. Quantum Elect., 14 (1990), 760.

[22] Goncalves R.S., Barrozo P., Cunha F., Thin Solid Films, 616 (2016), 265.

[23] Kangarlou H., Nasseri L., Tohidi T., J. Basic. Appl. Sci. Res., 2 (2012), 4807.

[24] Wen L., LeE. L., Mater. Chem. Phys., 110(2008), 393.

[25] Kangarlou H., RafiZadeh S., Opt. Spectrosc. +, 16 (2014), 1149.

[26] Bahae M.S., SAid A.A., TAI-Huei W., DaVid J.H., STRYLAND VAN E.W., IEEE J. Quantum Elect., 26 (1990), 4.

[27] Perdew J.P., Chevary J.A., Vosko S.H., Jackson K.A., Pederson M.R., Singh D.J., Fiolhais C., Phys. Rev. B, 46 (1992), 6671.

[28] Perdew J.P., Ruzsinszky A., Csonka G.I., VyDrov O.A., Scuseria G.E., Constantin L.A., Zhou X., Burke K., Phys., Rev. Lett., 100 (2008), 136406.

[29] Blaha P., SchWARZ K., WIEN2k, Vienna University of Technology, Vienna, 2009.

[30] Kisi E.H., Elcombe M.M., Acta Crystallogr. C, 45 (1989), 1867.

Received 2017-11-03

Accepted 2019-01-02 